\title{
LA CATEGORÍA JURÍDICA DE LA TIERRA EN HISPANIA ROMANA
}

\author{
$M^{a}$ CARMEN SANTAPAU PASTOR \\ Universidad de Alicante
}

\begin{abstract}
En este trabajo analizamos la categoria jurídica de la tierra en Hispania romana a partir de las referencias del derecho. Estudiamos la existencia de diferentes áreas socioeconómicas donde las formas de propiedad de la tierra son diversas. Utilizamos las inscripciones catastrales como herramientas para analizar la implantación de estatutos jurídicos diferentes.
\end{abstract}

This paper analyses the legal status of land in Roman Hispania on the basis of legal references. We study the existence of different socioeconomic areas with different forms of ownership of the land. Land registry inscriptions are used as a tool for analysing the establishment of different juridical statutes.

\section{LA ROMANIZACIÓN DE HISPANIA}

Durante un periodo de unos tres siglos la Península lbérica conoció el establecimiento de gentes itálicas. Este establecimiento, concretado la mayoría de las veces en la fundación ex novo de ciudades o en la reorganización de antiguos núcleos urbanos, fue desarrollándose y adquirió con el tiempo solidez.

Tanto en Italia como en las provincias, la creación de las diversas civitates fue siempre obra de la administración romana. Una vez que el ejército se adueñaba de un territorio, se procedia a tomar datos para la elaboración de un censo que cuantificaba la población y los recursos, entrando en escena a continuación los técnicos en agrimensura, midiendo y valorando la tierra; con las informaciones vertidas al respecto, se fijaban los límites territoriales de cada civitas a la que se concedia un territorio de explotación, disponiéndose así de los medios precisos para aplicar las cargas impositivas correspondientes. Durante todo este proceso organizativo, el estado romano era libre de respetar la realidad prerromana asi como de remodelarla para adaptarla a su propio modelo de civitas, como hizo muy a menudo ${ }^{1}$.

La ciudad hispana como una apuesta pormenorizada dentro de la globalidad roma- na, nos lleva a optar por una visión de contraste entre la esfera de acción del Estado frente a la ciudad, definiendo el espacio jurídico-político de ésta por confrontación y/o por similitud con la estructura de control que personaliza Roma.

La concesión de un estatuto jurídico particular a cada ciudad se orientó, pues, dentro del siguiente marco de referencia: las colonias y municipios quedaban organizados según las directrices emanadas de Roma, mientras que las demás formaron el grupo de las ciudades peregrinas y no gozaban de los privilegios inherentes en el derecho romano y latino, lo que les permitía gobernarse por las normas y usos consuetudinarios, siempre que éstos no atentaran contra la hegemonía y el poder político romano. Ahora bien, muchas de estas ciudades, por iniciativa propia, fueron adaptando sus formas de gobierno y de administración a las de las colonias y municipios antes de verse obligadas a efectuar el cambio, porque deseaban acceder a un rango superior dentro de la consideración jurídica urbana (Mangas, 2001, 11).

\footnotetext{
${ }^{1}$ Keay, 1996: 162. Para obtener una visión general de síntesis de las fundaciones y reorganizaciones de núcleos urbanos, Mentxaka, 1993, 27-32.
} 
Evidentemente, un salto cualitativo en este proceso fue la reforma de Vespasiano con la concesión del derecho latino a toda Hispania. La posesión del ius Latii otorgó a todas las comunidades hasta ahora peregrinas el derecho de establecer un municipium iuris Latii, en otras palabras, la posibilidad de instaurar una comunidad urbana con asamblea popular, ordo decurionum y magistrados regulares y, además, de brindar la posibilidad a los ciudadanos de obtener la civitas romana por desempeñar cargos municipales (Daza, 1990, 243; Alföldy, 1998, 16).

El derecho latino, por tanto, intervendrá en el ámbito local preparando el contexto político-jurídico que, sumado al desarrollo urbano, auspiciará el nacimiento del marco físico susceptible de conducir una fructífera municipalización. El desarrollo de este proceso histórico, favorecerá, en algunos casos, la conversión de estas comunidades en ciudades propiamente romanas ${ }^{2}$.

En pleno siglo II d.C. Ias colonias y municipios de Hispania, como las del resto de las provincias europeas y africanas, empiezan a denominarse res publica de modo indiferenciado, porque también las diferencias han desaparecido de facto (Gascou, 1979, 383-398; Alföldy, 1987, 92-98). En el siglo III d.C. todas las ciudades son civitates, sin rastro de la antigua diferenciación jurídica, lo mismo que todos los individuos son "ciudadanos". Las mutaciones económicas y sociales habidas en el cuerpo vivo del Imperio llevaron a la mutación del derecho y del sistema político (Abascal y Espinosa, 1989, 218).

La situación descrita alcanza un punto álgido en la primera mitad del siglo III d.C. A partir de la Constitución de Caracalla de 212 d.C., cuando se borre la diferencia entre los distintos estatutos jurídicos de las ciudades, adquirirá toda la población libre del Imperio el derecho de ciudadanía romana ${ }^{3}$.

La concesión vespasianea del ius Latii a toda Hispania y la extensión de la ciudadanía a todo el Imperio por Caracalla eran sanciones legales a una dinámica imparable, que tarde o temprano se hubiesen tenido que producir.

\section{LA ORDENACIÓN ECONÓMICA Y LA CUES- TIÓN DE LA TIERRA}

Hispania jugó, desde los primeros momentos de contacto con los colonizadores itálicos, un papel fundamental en cuanto al desarrollo y consolidación del sector agropecuario en ese tiempo. La Península Ibérica presentaba amplias posibilidades para reforzar este potencial económico que ya venía expandiéndose por todo el territorio itálico ${ }^{4}$.

Sabemos que en la cultura romana el fundamento económico de la potencia gentilicia era la propiedad de la tierra. El control del ager publicus y la posibilidad de participar en el disfrute de tales territorios, constituía la forma esencial de enriquecimiento con que contaban los diversos grupos sociales 5 .

La aparición en el primer plano de la historia de Roma de la figura del ager publicus coincide con la época de más intensas confrontaciones entre los patricios y los plebeyos, sobre todo durante el primer siglo de la república. Las fuentes dan buena cuenta de esta situación de conflicto socioeconómico y de las continuas agitaciones que se conocieron en los distintos momentos reivindicativos del proceso (Capogrossi, 1981, 4).

Los anhelos impetuosos de tierra eran respaldados por diferentes posicionamientos, en la teoría y en la práctica, dependiendo del estatus socioeconómico del individuo que los reivindicase. En torno a la figura políticaeconómica-social-jurídica del ager publicus, se encontraban condensados los desencuentros entre patricios y plebeyos desde finales de la monarquía a los primeros siglos de la República. Si los ciudadanos más poderosos obstaculizaban el acceso de los plebeyos a la tierra, los mismos plebeyos encontraban en su precaria situación económica un problema para

2 Galsterer, 1996, 211-221. Para el caso de la Meseta, Mangas, 1996, 223-238. Para el caso de Lusitania, Le Roux, $1988,39-49$ y $1996,239-253$. Para el caso de la zona de Levante, Abascal, 1996, 255-283. En general sobre los municipios de derecho latino, cf. la obras de Ortiz de Urbina, 2000 y García Fernández, 2001.

${ }^{3}$ La extensión del derecho de ciudadanía romana no afectará ni a la población bárbara asentada en el interior del Imperio, ni a la población de Egipto. Nicolet, 1982, 25; Fernández Nieto, 1982, 168; Ortiz de Urbina y Santos Yanguas, 1996, 8.

4 Acerca del rol que desempeñó Hispania, cf. Pena, 1994b. 329-337.

5 Capogrossi, 1981, 3; id., 1982, 1984 y 1988, 156-161; De Martino, 1985, 53; Rodríguez Neila y Navarro, 1999, 13, plantean una interesante reflexión respecto de los lazos de clientela y patronato y cómo a partir estos lazos de dependencia se asentaban las relaciones sociales y ciertos factores jurídicos. Este aspecto se relaciona perfectamente con las situaciones que surgirian entre individuos cuando se tratase de la propiedad y del trabajo de la tierra. 
la adquisición y puesta en producción de las parcelas; se encontraban en inferioridad de hecho, frente a los patricios, dado los medios económicos que necesitaban para la puesta en funcionamiento del fundo y la falta que tenían de los mismos (Finley, 1977, 158; Capogrossi, 1981, 6).

En esta situación, un punto central será la disolución de la más antigua tradición agraria a favor de un nuevo tipo de hacienda agrícola caracterizada, junto a una mayor extensión de terreno, por una mayor concentración de capital y sobre todo por la utilización a gran escala de mano de obra servil.

Esta transformación de la propiedad agraria ve la luz en el período que va de finales del siglo III al I a.C. A este respecto, hay que decir que para entender cuál es el régimen de la tierra en época Republicana y cómo las provincias vienen a suponer un aporte esencial en este sentido, no podemos perder de vista que los aspectos institucionales y las transformaciones jurídicas a lo largo del tiempo conformaron las peculiaridades de esta situación en la que la escasez y los deseos de tierras eran la nota dominante (Capogrossi, 1981, 235-236).

Retomando la exposición con el contexto socioeconómico que existía en Hispania, es necesario apuntar que frente a una situación algo crítica para el sector agrícola en la Península Itálica, encontramos aqui una situación bastante diferente. Hispania ofrecía unas condiciones favorables para trabajar el campo en sus fértiles tierras del valle del Ebro y del Guadalquivir (Ponsich, 1974 y 1979; Greene, 1990: 110-111; González Román, 1997, 20; Santos, 1998, 19), un panorama político más tranquilo que en tiempos anteriores y una gran riqueza mineral. Estas situaciones propiciarian el inicio y desarrollo de un vasto proyecto colonizador, encontrándose la posesión de la tierra entre los objetivos primarios de la empresa (Roldán, 1989, 24; Ariño y Díaz, 1999, 153-192).

En este sentido, por tanto, la crisis económica que vivía la Península Itálica no favorecía a la pequeña propiedad que, además, se vio gravemente afectada como consecuencia de la guerra social. Un buen número de campesinos rozaría la situación de pobreza absoluta, de ahí que muchos emigrasen a la capital. Una vez alli, sin una solución para su desesperada situación, se alistarían en el ejército, teniendo en mente la ilusión de que, tras el período de guerra propiamente dicho, volverían a Italia, licenciándose y adquiriendo una parcela de tierra, por qué no, en propiedad (Roldán, 1989, 26). Estamos hablando de un tiempo en que se conoce la progresiva desaparición de la mediana y pequeña propiedad, aumentando el número de latifundios ${ }^{6}$ trabajados por esclavos (De Martino, 1989, 217238; Carandini, 1989, 101-200; De Martino, 1993, 5-25; Carandini, 1995, 31-36).

La progresiva difusión e implantación de la civitas que se produce en las provincias hispanas se materializa en el territorio con las deductiones de colonias y las promociones al estatus de municipio, por tanto, implantándose nuevas situaciones juridicas (Mentxaka, 1993, 27). Estas nuevas situaciones jurídicas condicionarán el devenir de la comunidad descle el punto de vista de la economía de ese territorio, de la posición y papel de los distintos grupos sociales y de la situación políticoadministrativa del territorio. Esta coyuntura que se desprende de la situación jurídica (el estatus jurídico de una determinada comunidad), por tanto, condicionará toda la realidad histórica de las comunidades desde su relación con la tierra hasta sus derechos políticos, etc?

Durante la etapa republicana y altoimperial, Roma posee el control sobre la propiedad de la tierra provincial. Este dominio sobre una tierra explotada normalmente bajo el régimen de la cesión a las comunidades indígenas en régimen de arrendamiento, por tanto bajo el título de possessio, puede detectarse, en parte gracias al listado de ciudades estipendiarias hispanas de las que Plinio deja constancia (nat. $3,3,7 ; 3,4,17 ; 3,4,18$; González Román, 1999, 141).

\section{LA ORGANIZACIÓN Y DISTRIBUCIÓN DEL AGER PROVINCIALIS}

La idea romana de ciudad vista como el máximo bien, como la cumbre de todo el

\footnotetext{
6 Ya hemos indicado que el latifundio era la realidad económica que más auge comenzaba a tomar, y las fuentes nos informan de ello. Plinio, nat. 18, 6, 36, era consciente de la decadencia de la agricultura itálica, mientras que Columela (agr. 1, 3, 12), por su parte, censuraba que los latifundios se abandonaran al pasto extensivo y que existiesen fincas de extensiones prácticamente inabarcables. La progresiva concentración de las tierras es uno de los fenómenos más significativos de la evolución de la estructura agraria de época imperial.

${ }^{7}$ Esta idea, entre otras, es el eje central a partir del que se estructura la obra de Marín, 1988. En concreto podemos verio en Marín, 1988, 7.
} 
progreso humano y social, era el modelo de comunidad que se quería implantar en cada uno de los territorios que eran anexionados a Roma (Pérez Centeno, 1999, 7).

La ciudad no significaba sólo el núcleo urbano, sino también una comunidad política organizada y asentada en un territorio propio con un centro urbano (López Paz, 1994, 331). Ciudad y campo vivian de una manera recíproca y necesaria su dependencia. Se trataba de una relación activa e irremisible para que la comunidad funcionase desde un punto de vista administrativo y financiero (Pérez Centeno, $1999,8)$.

Se creaban de esta manera núcleos urbanos que, aunque dependiesen del poder central, contaban con un territorium perfectamente delimitado. Esta territorialidad del dominio romano se traducía en un control de un espacio estratégico -el ager-por la significación de su valor socioeconómico (Simmel, 1983, 221-242; Zaccaria, 1995, 9-54).

La delimitación del territorio era un procedimiento imprescindible para evitar la confusión en materia de tierra con las comunidades circundantes y entre las mismas fincas de los particulares de la ciudad (Jiménez Salcedo, 1999). Toda comunidad urbana, independientemente de la categoría jurídica que tuviese, contaba con un territorium; sus límites marcaban la iuris dictio de los magistrados de cada comunidad y definian también los territorios en que podían ser exigidos los munera ${ }^{8}$.

La idea de delimitar los confines de un territorio es un reflejo del trasfondo ideológico y político de la conquista ${ }^{9}$. Tanto la confiscación de tierras y su acondicionamiento, como la redistribución de la propiedad, se acompañan de una división del suelo y de un amojonamiento de las parcelas, necesitando instrumentos de mesura de precisión (Moatti, 1993, 3).

Centuriatio y limitatio, como formas romanas de organizar el territorio, son la base física y jurídica sobre la que se desarrolla la propiedad privada de las tierras. Dada la importancia que conllevaba el procedimiento, ambas fases debian estar perfectamente definidas y concretadas dependiendo del territorio que se tratase (Bradford, 1957; Favory, 1983, 51-55).

La historia de la colonización en Hispania ${ }^{10}$, como en otros territorios provinciales, va asociada a la historia de la agrimensura. Estamos hablando del control social, fiscal y administrativo de la tierra y, por extensión, de los ciudadanos ${ }^{11}$.

El proceso colonizador, como cualquier otra empresa de envergadura que se iniciase, conocería dos momentos álgidos: el primero, el de la decisión política y el segundo, el de la ejecución del mismo. Para gestionar el aprovechamiento agricola de las regiones conquistadas por Roma, progresivamente, se extendió el modelo de centuriaciones en un proceso de homogeneización de situaciones que se impuso sobre situaciones topográficas y culturales diversas ${ }^{12}$.

A una escala más reducida, dentro del propio territorio municipal y frente a la delimitación del territorio entre comunidades diferentes, se establecian otros límites que determinaban las distintas categorías de suelo, sobre todo, las que diferenciaban las propiedades privadas de las tierras de patrimonio público.

Vemos cómo, a lo largo del proceso colonizador, existe una preocupación constante por entregar a los beneficiarios de las asignaciones tierras fértiles para el cultivo. A estos terrenos de cultivo serán añadidos bosques y pastos necesarios para conseguir explotaciones

\footnotetext{
${ }^{8}$ El catastro además de ser un sistema con el que organizar grandes superficies de territorio y uno de los elementos claves de la romanización, sería el instrumento para gestionar el asentamiento de la población y la explotación económica del territorio y a partir del cual recaudar los impuestos. Déléage, 1934, 73-228; López Paz, 1994, 264-265; Ariño, Gurt y Martín Bueno, 1994, 309; Pérez Centeno, 1999, 7.

9 Sobre el reflejo politico en el proceso de centuriación de nuevos territorios: Gabba, 1985, 265-284; Chouquer y Favory, 1992.

${ }^{10}$ Aunque en este apartado no se tratará en detalle las fases y cronología de la colonización, hemos recurrido a obras de gran relevancia para analizar la relación entre las características políticas del proceso y los distintos momentos por los que pasó la cuestión del ager provincialis. Entre las obras más destacables cabe mencionar: MacMullen, 1963, 107ss; Salmon, 1969, 13ss; Dilke, 1979: passim; Keppie, 1983; Mann, 1983; Keppie, 1984.

11 Moatti, 1993: 4. Resultan muy interesante al respecto las reflexiones de Curchin, 1994, 87-102. A lo largo de estas páginas, el autor utiliza el concepto de social control, con lo que explica el control social y administrativo que ejerció Roma sobre las provincias, analizando en concreto el caso de Hispania. Con socia/ contro/ se refiere al dominio ejercido a través del organigrama administrativo, político y judicial desplegado por Roma en suelo provincial.

12 Con una visión más detallada sobre las técnicas que se aplicaban dependiendo de las caracteristicas del territorio a la hora de delimitar las parcelas, Dilke, 1971, passim; Hinrichs, 1974, passim; Gabba, 1985, 265-284.
} 
agrarias viables y eficientes. Este principio motor, el de la preservación de la productividad, no se rige únicamente con el fin de proteger los intereses privados, la economía de los particulares. La protección de estos intereses conllevaba en última instancia la pervivencia del cuerpo cívico, de la comunidad.

A las evidentes connotaciones económicas que representaba la tenencia de una porción de tierra para la seguridad y perduración de la colectividad ciudadana, hemos de sumar los factores psicológicos que también contribuirian a fomentar los deseos de poseer una parcela cultivable. La tierra aparece como símbolo de lo permanente, de lo inalterable, frente a otras actividades económicas (piénsese en el comercio de las manufacturas).

La tierra se presenta como un elemento rentable a manos de su propietario que no parece cambiar; día tras día el bien, trabajado debidamente, da sus frutos. Esta idea de perpetuidad, de elemento que se enraíza con las tradiciones mismas de una familia, harian de la tierra no sólo una forma de supervivencia, sino una actividad económica perfectamente asentada en el imaginario cultural de la colectividad, en este caso de la romana.

\section{LA PROPIEDAD DE LA TIERRA Y LOS PRE- CEPTOS DEL DERECHO ROMANO}

El derecho romano proporciona una base teórica desde la que entender ciertas conductas socio-económicas que se dieron en la Antigüedad, en concreto, para analizar la cuestión de las tierras que entraron a formar parte del control romano. La adquisición de tierras, la posesión o propiedad de las mismas, no se entiende únicamente desde las acciones políticas proyectadas en las empresas coloniales dirigidas por la metrópolis. La esfera de actuación desde la que emanaban decisiones como la de fundar nuevas ciudades, limitar y organizar los terrenos circundantes o la de repartir en parcelas el campo una vez delimitados sus confines, cobra sentido cuando se analizan los preceptos legislativos que dieron luz verde a todas esas acciones estatales.

La base sobre la que se consolidó la expansión romana en suelo hispano fue el concepto de populus Romanus. La idea de populus Romanus, concebida como política y no étnica, fue la base a partir de la que se aplicó el dominio romano en cualquier punto de la geografía hispana, ya que al no sustentarse en concepto étnico, no excluía la participación de ningún grupo social hispano, y de ahí su "éxito". Ello se entiende a partir de la combinación de dos principios teóricos que se pusieron en práctica, como son la adición de ciudadesestado a la comunidad hegemónica romana y la incorporación al propio cuerpo político de las comunidades vencidas (Roldán, 1989, 14).

Las nuevas comunidades se anexionaban a Roma pasando a formar parte del ager Romanus, convirtiéndose la capital en el núcleo político de un extenso territorio en el que se iría generalizando la adquisición de la ciudadanía romana. Las élites locales, las primeras beneficiarias de la ciudadanía, conservarian los derechos de sus correspondientes comunidades, quedando incorporados ya, por otro lado, como una capa social más del estado romano y gozando de derechos políticos propios del ciudadano (Alonso y Cerrillo, 1987, 463-470; Bravo, 2001, 73-74).

Para entender el proceso no podemos perder de vista que esta promoción políticosocial de las élites fue en paralelo a la promoción de las ciudades y al desarrollo urbanístico de los núcleos urbanos, con el fin de asemejarse a la que poseía los rasgos de la ciudad-estado ideal, a Roma ${ }^{13}$.

En suelo itálico y posteriormente en las provincias, la ciudadanía y urbanización conducirían a la transformación jurídica de las comunidades con organización urbana. Para este caso, la Península Ibérica constituye un espacio privilegiado donde se pondrán en práctica las políticas de colonización llevadas a cabo por César y continuadas por Augusto (Roldán, 1989, 16; Roddaz, 1996, 13). Desde el primer momento en que se toma contacto con la realidad desconocida de las provincias, se irán implantando aquí algunos de los rasgos más característicos de la cultura romana.

Pero no podemos obviar un dato relevante acerca de estos encuentros entre los dos grupos poblacionales: la romanización de las provincias produce un efecto reflejo de provincialización de Roma, apreciable desde finales del siglo I d.C. Esta presencia política y

\footnotetext{
13 Marín, 1988, 7. En cuanto al término ciudad, hemos de entenderlo con un sentido ambivalente, ya que haria referencia tanto a lo que podríamos llamar la ciudad como ordenamiento político, como al carácter estrictamente urbanístico. En concreto, en época romana se distinguieron perfectamente los términos civitas y urbs; el primero se utilizaría para hablar del ordenamiento socio-político del núcleo urbano, mientras que el segundo se emplearía para hablar de la estructura material de la ciudad.
} 
cultural de provinciales en la metrópolis sigue un orden semejante al de romanización de aquéllas, siendo frecuente que los territorios que con mayor rapidez y profundidad habian sido romanizados produjeran los primeros grupos provinciales relevantes en la ciudad de Roma (Bética y Tarraconense) (Morales Arrizabalaga, 1995, 26).

En la conquista del suelo hispano es necesario tener en cuenta a las gentes que participaron en dicho proceso: militares y población civil, itálicos de variada extracción social que llegaban a tierras hispanas con el beneplácito de Roma. Aunque todos ellos no fuesen ciudadanos romanos, el influjo cultural de la metrópoli viajaba hasta Hispania con ellos, ya que como itálicos procedian del ámbito cultural romano ${ }^{14}$

Por otro lado, la presencia estable del ejército en Hispania habia llevado al asentamiento de soldados y aliados itálicos en estas provincias que, al licenciarse, adquirirían un nuevo papel en la Península, esto es, el de colonos agrícolas. Estos colonos serian el motivo, en muchas ocasiones, de la creación de ciudades donde convivirán itálicos e indígenas, centros urbanos que, como ya hemos comentado, actuarán como verdaderos focos romanizadores ${ }^{15}$.

La opinión general apunta que parece difícil pensar en una aplicación general del ius civile antes del s. Ill d.C; a partir de ese momento, transcurridas varias generaciones de magistrados municipales, se produciría un ascenso generalizado por parte de la población autóctona a la plenitud del derecho romano. La romanización general de la península podemos considerarla iniciada con el Edicto de Vespasiano y, por tanto, a partir el último tercio del siglo I d.C. Hasta ese momento, únicamente se había conocido una romanización espontánea, concentrada espacialmente en la Bética, la costa mediterránea y el valle medio y bajo del Ebro, zonas donde la presencia romana era intensa desde hacía ya mucho tiempo (Morales Arrizabalaga, 1995, 75).

El punto de partida de las modificaciones que se operan está constituido por los cambios del marco jurídico de la propiedad de la tierra a fines de la república y comienzos del imperio. Concretamente, la fundación de colonias y la promoción municipal permiten el acceso a la propiedad de la tierra (dominium) de los individuos de las provincias, que forman parte de estas ciudades; en consecuencia, se modifica sustancialmente la situación que apre- ciábamos tras la conquista, que convierte el ager provincialis en propiedad del Pueblo y del Senado Romano en calidad de ager publicus (González Román, 1999, 164-165).

Las actuaciones jurídicas que se emprendian durante los períodos de colonización se encuadran dentro del denominado derecho público, ya que se regulaba la estructura y las atribuciones de las autoridades y sus relaciones con los ciudadanos particulares. Por tanto, pensamos que cuando se limitaban los campos y se asignaban a particulares, dicho proceso tenía lugar dentro de la órbita del derecho público puesto que la decisión de proceder a la repartición de tierra venía dada por el poder político del estado, siendo también éste -y por extensión el senado local- quien tomaría cartas cuando existiesen conflictos con tierras no centuriadas y que le pertenecían.

Si bien este dato es cierto, no podemos olvidar que cuando se trataba de tierras coloniales de uso comunal o particular, en la resolución de conflictos o en la elaboración de disposiciones juridicas, podría intervenir tanto el derecho privado como el derecho público. Sin embargo, una vez que las tierras eran distribuidas y a cada particular le habia sido otorgada una determinada parcela de suelo cultivable era el derecho privado el encargado de regular las relaciones entre los propietarios de la tierra.

Pese al nuevo marco jurídico que posibilita el acceso a la propiedad, el sistema resultante debió de diferir, especialmente, en lo que se refiere a las dimensiones que posee en cada ciudad y en su conjunto. El fenómeno puede apreciarse, concretamente, en las fundaciones coloniales, que llevan implícita un reordenamiento de la propiedad de la tierra, que se le asigna a la nueva ciudad. Concretamente, la ley fundacional de Urso (cap. 82) documenta la existencia dentro del territorio delimitado de lotes de parcelas asignadas como propiedad privada y de tierras públicas, propiedad de la colonia; la utilización que se hace de ellas permite diversas variantes, que van desde el

\footnotetext{
14 En el estudio de la emigración itálica en Hispania, del desarrollo de las formas de organización urbana, de la procedencia y del status jurídico de los individuos que llegan a la Peninsula, destacan las siguientes obras: Haley, 1986; Marín, 1988, 47-112; Haley, 1991, 27-83 (esp. 53-60 para Lusitania, 61-68 para Baetica y 69-83 para Tarraconensis); Le Roux, 1995, 21-34 y 52-58.

15 Brunt, 1962, 69-86. Para el caso de Hispania, Roldán, 1974; Roldán, 1976; 125-145; Roldán, 1989, 25; Roldán, 1996, 101-123; Roldán, 1998, 233-242.
} 
uso colectivo al arrendamiento (locatio) por periodos no superiores a cinco años (González Román, 1999, 165).

La desigualdad de las propiedades resultantes constituye una práctica inherente a las propias fundaciones, ya que en las distribuciones se tiene en cuenta la condición social de los que participan; el fenómeno se aprecia específicamente en las colonias militares, donde los mandos de las legiones suelen recibir un lote y medio o dos o más que los simples veteranos $^{16}$

La evolución ulterior del sistema se ve condicionada por distintos factores, que pudieron propiciar la concentración de la propiedad de la tierra; entre ellos se encuentra el endeudamiento propiciado por malas cosechas, o las propias relaciones familiares, que establecen las élites aristocráticas. Pero, además, debe tenerse en cuenta que en ocasiones parte del territorio asignado a una ciudad quedó catastrado sin uso específico (subseciva) ${ }^{17}$.

\section{LA TIERRA EN EL DERECHO ROMANO}

Cuando hablamos de la propiedad, en concreto de la tierra, la legislación, sobre todo en los primeros momentos de su andadura, englobaba una serie de elementos que aparecian indisolubles con la parcela de tierra propiamente dicha. Estamos hablando de la casa, de los animales, de los aperos de labranza, de los trabajadores, etc. En esta idea se fundamentan las diversas teorías que explican los fundamentos y el desarrollo de la propiedad en Roma.

Aunque los romanos no contaron hasta un momento avanzado de su historia con un concepto abstracto sobre la propiedad recurrieron siempre al término mancipium, que refiere a una realidad más amplia que el concepto de propiedad. Ya a partir de textos de época clásica y justinianea los dos términos que más se emplean son el de dominium y propietas (Ortega, 1991, 56-57).

A partir de la Ley de las XII Tablas encontramos ya implantado el concepto de propiedad privada incluso sobre los fundos, identificándose con lo que hoy llamamos propiedad individual. Pero sabemos que, durante los dos últimos siglos de la época republicana, Roma conoció cambios muy significativos en su organigrama político y, por tanto, jurídico; tales cambios influirían en el antiguo concepto de propiedad que sufrirá también importantes transformaciones.
Dominium, el término más antiguo y quizás el más amplio, deriva de domus (casa), de ahí que su significado básico fuese el del "señor de la casa" y, por extensión, su dueño o propietario. Los términos dominium y dominus, a partir de la segundo mitad del s. II d.C., fueron desplazados por los de proprietas y proprietarius que, como indican, se utilizaron para designar la propiedad y el propietario.

\section{LA PROPIEDAD PRIVADA DE LA TIERRA}

Originariamente, el dominium ex iure Quiritium era la única especie de propiedad que el derecho romano conocía. De Gayo aprendemos que en los momentos más arcaicos de la historia de Roma o se era propietario ex iure Quiritium, o no se podia ser propietario, ya que no existian situaciones sustitutivas, paralelas o análogas (Gayo, 2, 40). Para que se llegase a la situación de ser propietario era necesario que existiesen varias condiciones: como la capacidad en la persona, la idoneidad en la cosa, y un modo específico y determinado de adquisición (Ortega, 1991, 47).

No hemos de perder de vista los sujetos que podían ser titulares del dominium ex iure Quiritium: por un lado, los ciudadanos romanos y por otro, los latinos y peregrini que tuviesen el ius commercii. Sólo a éstos se reconoceria el derecho absoluto y exclusivo de disponer del suelo (Ortega, 1991, 47; Gómez Royo, 1997, 36). Sabemos también, que aunque el ordenamiento romano no reconocía a los peregrinos sine commercio la posibilidad de adquirir el dominium ex iure Quiritium, sí les reconocían la titularidad de los derechos reales establecidos y protegidos por sus leyes locales, siempre que Roma las hubiese mantenido. Además contarían con la ayuda y el asesoramiento del pretor peregrino, el pretor urbano y los magistrados en las provincias, contando probablemente con actiones ficticiae en cuyas formulae se disponía que, ante un litigio judicial, el iudex juzgara como si el peregrino fuera ciudadano romano (Volterra, 1986, 314).

\footnotetext{
16 Para el caso de Emerita, Gorges, 1979, 99.

17 Con el nombre de subseciva se entenderían todas aquellas tierras que no pudieron ser objeto de asignación por las condiciones del suelo-si era estéril por ejemplo- y aquellas otras que por sus características orográficas no posibilitaban el trazado de centurias completas. A su vez, también se empleaba para denominar aquellas tierras que tras el final de la asignación sobraban. López Paz, 1994, 232; González Román, 1999, 165; Mateo, 2001, 180-181.
} 
En este sentido, también conocemos casos en los que tanto romanos como pueblos extranjeros se concedieron ventajas recíprocas bajo los nombres de conubium y commercium. Nos interesa especialmente el segundo tipo, que como hemos comentado anteriormente permitiría entre ambos colectivos la venta y la compra de propiedades, según los modos del derecho civil, lo que conllevaría, entre otras cosas, la mancipatio, la facultad de convertirse en acreedor o deudor por el nexum (tipo de contrato) y la posibilidad de utilizar la usucapio. Se añadió después la factio testamenti o capacidad de hacer testamento y el commercium agrorum, que era el derecho de adquirir inmuebles en el ager romanus (Declareuil, 1958, 40-41).

Cuando no existía la concesión del derecho Itálico el Estado, igualmente, concedía en diferentes formas y bajo diferentes aspectos parcelas de ager publicus, esto es, de los fundos que eran propiedad del populus Romanus (sobre todo en zonas de conquista). Esta tenencia de la parcela concedida no se produciria en régimen de propiedad privada, por lo que seguiría perteneciendo al estado; el particular, sobre la parcela asignada, tendría únicamente el derecho de posesión (Volterra, 1986, 315).

A partir de esta situación conocida se produjeron cambios y novedades en las formas de adquirir la propiedad, de la misma manera que la sociedad iba modificando sus estructuras más elementales con el paso del tiempo (Ortega, 1991, 48). Estas nuevas formas de adquirir propiedad responden a la necesidad de legitimar la situación en las provincias. Dichas formas son denominadas por el derecho actual a partir de un fragmento de las Instituciones de Gayo $(2,40)$ como propiedad pretoria ${ }^{18}$, propiedad de los fundos provinciales ${ }^{19}$, y la propiedad peregrina ${ }^{20}$.

\section{PROPIETAS VERSUS POSSESSIO}

En época romana, sobre todo hasta el siglo III d.C., el número de possessores en el campo era mayor que el de propietarios (Rascón, 2000: 207).

Muchos trabajos han recogido, si no como tema central si en alguna de sus partes, el tema de la controversia entre los términos y las realidades a que respondian tanto la propiedad como la posesión (Villers, 1977: 265273; Schmidlin y Cannata, 1984: 93-118).
Ulpiano advirtió que la propiedad debía distinguirse de la posesión (D. 43, 17, 1, 2, y D. 41, $1,2,12,1)$, idea que también manifestó Venuleyo (D. $41,2,52$, pr.); sin embargo, ninguno de estos autores elaboró un concepto de aquélla.

Siguiendo la opinión de la mayoría de los investigadores, creemos que los juristas del principado entendieron la posesión como la tenencia de hecho sobre una cosa, pudiendo disponer de ella con exclusión de los demás. Entendida así, los elementos que configurarían esta posesión serían el corpus o tenencia material de la cosa y el animus o convicción de tenerla como propia (Rascón, 2001, 205-206). En cualquier caso, se trataba de tener la disponibilidad inmediata de una cosa independientemente de quien tuviese el derecho de propiedad sobre la misma (Carcaterra, 1967; Schmidlin y Cannata, 1984, 119-150). Lo que aparece claro en las fuentes es que, normalmente, el que era el propietario era el poseedor de la cosa, pero propiedad y posesión no siempre eran atributos en la misma persona ${ }^{21}$.

El origen de la possessio es dudoso y se ha querido ver en diferentes situaciones, Por un lado, se ha tratado de encontrar su génesis en las concesiones de tierra, que el pater desde la propiedad del grupo familiar agnaticio hacía a los clientes, quienes la devolverian cuando su verdadero dueño la reclamase; esta situación constituia lo que los juristas definian

\footnotetext{
${ }^{18}$ Como propiedad pretoria conocemos la ausencia o defecto en el modo legítimo de adquisición. En ocasiones un individuo, habiendo adquirido la disponibilidad de una cosa y respetando los derechos ajenos, no pasaba a ser un verdadero dominus, ya que la adquisición de la misma no se había llevado a cabo siguiendo las normas y los procedimientos del ius civile. Con el paso del tiempo, se podía adquirir la propiedad de la cosa, es decir, convertirse en dominus, a través de la usucapio. Ortega, 1991, 49.

${ }^{19}$ Cuando se habla de la propiedad de los fundos provinciales se suele hablar de idoneidad de la cosa, siempre y cuando no se contase con el ius Italicum del suelo.

20 Hablamos de propiedad peregrina cuando se daba una situación de falta de capacidad jurídica en la persona.

21 Para ver las relaciones entre propiedad-posesión, Schmidlin y Cannata, 1984, 109-110.

22 La posesión se podía adquirir directamente por el paterfamilias, por persona sometida a su potestad o por el procurator omnium bonorum (administrador general de sus bienes), que actuaba en nombre de aquél. Si el paterfamilias entregaba el objeto en arrendamiento o depósito retenía la posesión mediante quien lo detentaba. Pero si lo entregaba en prenda, el paterfamilias retenia la possessio ad usucapionem.
} 
como precarium ${ }^{22}$. Otros autores, por el contrario, han creído que su origen se remontaba a las primeras concesiones del ager publicus.

Lo cierto es, que en los últimos momentos de la república la posesión era una institución independiente no demasiado clara dada la falta de una terminología concluyente y definitiva.

\section{LA POSSESSIO Y LA TENENCIA DEL AGER PUBLICUS}

El término comenzó por referirse exclusivamente al asentamiento en tierras del ager publicus en las que se conocía el dominium privado, ya el que el verdadero dominus era el Populus Romanus (Daza y Ennes, 1993, 203).

El ager publicus, originariamente, estaba destinado al pastoreo y a la agricultura, encontrándonos que todavía a fines del siglo II a.C. el suelo agrario presentaba como característica el predominio de su titularidad no privada. Pero, posteriormente, el impulso y el aumento de la actividad agrícola exigió la desaparición de la situación del precarium que vimos anteriormente y la implantación de la tenencia mediante possessio, que era revocable.

En el caso hispano, con la conquista de este ager publicus la tierra, normalmente, era gestionada en régimen de possessio y explotada por indígenas y por romanos (Pena, 1994, 329). El caso de la possessio del ager publicus provincialis contará con puntos en común y con características propias. Estos terrenos recién incorporados, que se fueron añadiendo progresivamente como nuevas tierras al ager publicus, permanecieron como susceptibles sólo de posesión.

Sabemos que a partir de la incorporación del suelo provincial al ager publicus se producirá una revitalización de la autonomía de las comunidades locales a la hora de organizar, por ejemplo, su sistema tributario romano (CastiIJo, 1996, 70-75). Por el contrario, frente a nuevos impulsos de la autonomía local, por encima de todo ello, estaba el reconocimiento de la existencia de otras formas de organización del territorio, fundadas sobre la concepción de dominium como mecanismo de articulación del imperium (Grelle, 1990, 174).

Exceptuando la tierra con ius Italicum, el término dominium no sería aplicable a los fundos provinciales que, por su titularidad pública, únicamente conocerían la del régimen de la possessio ${ }^{23}$. La figura jurídica más extendida en las tierras provinciales será la que consideraba ese suelo como ager vectigalis y sobre el que habria que pagar, a cambio de su uso y disfrute, un canon o vectigal (López Paz, 1994, 228).

Una forma común para la tenencia de estas tierras por parte de los indígenas parece que fue mediante el sistema de locatioconductio ya que, al tratarse de ager publicus, los indígenas no mantendrian sobre sus tierras conquistadas el derecho de propiedad; si querian continuar trabajando la tierra, viviendo del cultivo de los campos, cabría esa posibilidad siempre que pagasen un vectigal (Dopico y Pereira, 1993, 633-642; López Paz, 1994, 230). Sobre esto, tanto Gayo en sus Instituciones como un pasaje del Digesto nos muestran que estos arrendatarios mientras pagasen el canon estipulado por las autoridades no podrían ser expulsados y desposeídos de estas tierras (Gayo. 3, 145 y D. 6,3,1, pr.). Así, las fuentes jurídicas dejan muy claro que los arrendatarios de los agri vectigales tenían la possessio de estos fundos, pudiendo cultivarlos a perpetuidad e, incluso, pudiendo trasmitirlos a sus herederos ${ }^{24}$.

Además el arrendador contaba con la protección de la llamada actio vectigalis, un medio legal por el que podría demandar una situación injusta con respecto a la pertenencia del fundo que poseía (D. $6,3,1,1)$.

\section{COLONIZACIÓN Y CONCESIÓN A PAR- TICULARES DE AGER PUBLICUS}

Hoy sabemos que no conocemos todas las formas de ocupación y de concesión del ager publicus que puso en práctica el estado romano y ello, quizás, es debido a las diferentes

\footnotetext{
23 Sobre la naturaleza jurídica del suelo provincial encontramos notables referencias en las Instituciones de Gayo $(2,7 ; 2,14 ; 2,21 ; 2,27 ; 2,31 ; 2,32 ; 2,40 ; 2,46)$. Evidentemente, lo interesante de la cuestión gira en torno a la consideración del dominium que ejercía el Estado sobre estas tierras provinciales. Carrelli, 1935, 379-391; Bozza, 1942, 66-85; Bozza, 1943, 13-20; Daza y Ennes, 1993, 204; Orejas y Sastre, 1999, 160-161.

24 Las fuentes jurídicas complementan, por tanto, las informaciones que los agrimensores nos proporcionan sobre el estatuto jurídico de estos terrenos. Asi, el Digesto nos explica que los arrendatarios no pueden ser despojados de sus tierras mientras sea pagado el cánon exigido (D. 2, 8, $15,1$ y D. $6,3,1,1)$. Esta misma cuestión es puesta de relieve por el Jurista Gayo (Gayo. 3,145).
} 
y poco claras denominaciones sobre relaciones juridicas y formas de explotación que hallamos en los textos literarios y jurídicos.

Desde época temprana, junto a las concesiones de parcelas bajo el régimen de la possessio, se conocen asignaciones de parcelas de ager publicus en propiedad a particulares (ager divisus et adsignatus) y otras tantas diferentes formas de concesiones a los mismos como complemento de las primeras parcelas repartidas del ager publicus ${ }^{25}$. Evidentemente, también desde el comienzo de la colonización encontrariamos asignaciones a particulares que no se concedían como finca en propiedad del particular al que se le otorgaban sino como una possessio por la que pagarían un canon.

Para Hispania contamos con dos ejemplos excepcionales a la hora de investigar el régimen jurídico y las formas de propiedad/ posesión de las tierras asignadas en la fase colonial. Se trata de las dos inscripciones catastrales conservadas, la recuperada en Ilici (La Alcudia, Elche, Alicante) y la aparecida en las inmediaciones de la ciudad antigua de Lacimurga (al noroeste de la provincia de Badajoz, en el Cerro de Cogolludo, Navalvillar de Pela-Puebla de Alcocer).

La inscripción de llici nos presenta el caso de un territorio que una vez centuriado sería destinado a un conjunto de colonos romanos veteranos de guerra -los nombres de los cuales conocemos en parte gracias al texto conservado en la placa-. La ciudad sería objeto de una deductio colonial tras la victoria de César en Hispania, posiblemente en época triunviral $(43 \text { a.C. })^{26}$.

Ilici aparece en Plinio como inmune (nat. $3,3,19$ ) y en un texto del jurista Paulo (D. 50 , 15,8 .) como una de las ciudades hispanas que disfrutarian del ius italicum. El caso de llici es sintomático en el sentido que tiene el rango de colonia civium romanorum, cuenta con la immunitas y, además, con el ius Italicum ${ }^{27}$. Por tanto, posee todas las características para hablar de una ciudad en la que las gentes que residiesen adquirian, a medida que alcanzasen ambos privilegios, la propiedad privada de la parcela que les fuese asignada ${ }^{28}$.

Tanto la immunitas como el ius Italicum tenían una importancia vital para las provincias. Tras la conquista, el suelo provincial pasaba a manos del pueblo o del senado romano, explotándose conforme a los procedimientos indicados por los agrimensores: se podría vender como ager quaestorius (García Garrido, 1993,
31; De Churruca, 194, 52; González Román, $1999,140)$, arrendar como ager vectigalis (Garcia Garrido, 1993, 31; De Churruca, 1994, 52; Del Giudice y Beltrani, 1995, 49; González Román, 1999, 140), o incluso, tras una deductio, dar como ager datus et asignatus (García Garrido, 1993, 30; Del Giudice y Beltrani, 1995, 49; González Román, 1999, 140 ), es decir, otorgando la propiedad o posesión del mismo al particular que lo recibía. Ambos privilegios jurídicos venían a complementar -en beneficio del colono- las características que se desprendian de cada una de las categorias jurídicas que podia otorgarse a la tierra.

En el caso de la inscripción catastral de Lacimurga estamos ante un caso de possessio de tierras. Además es la primera vez que en la forma de una colonia se refleja ya la disposición de las parcelas en la centuriación de un territorio (Sáez, 1990, 207).

25 Volterra, 1986, 381-383. En estas páginas hace una descripción detallada de los rasgos característicos de cada tipo de ager que pasaba a formar parte del Estado romano y que podía darse a los particulares para diferentes usos y bajo diferentes condiciones jurídicas y económicas.

${ }^{26}$ Se maneja, mayoritariamente la fecha del 43 a. Cf. Ramos, 1974, 1975 y 1978; Ramos y Uroz, 1992, 98-100; Chao, Mesa, Serrano, 1999, 417-424; Mayer y Olesti, 2001, 109; Cavalieri, Olesti y Mayer, 2002, Dossier 1TA. Épigraphie.

27 A pesar de la parquedad de las fuentes y sus problemas de interpretación, la investigación llega al acuerdo con la idea de que ius italicum significa que la comunidad en cuestión y su territorio disfrutarian de los mismos privilegios jurídicos que Italia. Savigny, 1850, 320-352; Von Premerstein, REX, col 1238-1247; Luzzato, 1950, 79-110; Luzzato, 1974, 9-64; Sherwin-White, 1973; Bleicken, 1974, 359-414; Mazzarino, $1974,357-372$. Entre los beneficios que comportaba la concesión del ius Italicum destacan los siguientes (Saquete, 2000, 380): - La autonomía de la ciudad, sin conocer con exactitud si los habitantes podrian prescindir de la jurisdicción del gobernador provincial. -La exención de permitir o dar hospitalidad a guarniciones militares. -La propiedad plena de la tierra, el dominium ex iure Quiritium, susceptible de ser adquirida y transmitida mediante mancipatio, usucapio e in iure cessio. - La immunitas o exención fiscal tanto del tributum solis como del tributum capitis. De todas las características expuestas sobre este derecho, las dos últimas son las más aceptadas por los investigadores. La investigación general se decanta por aceptar unánimemente, sólo los dos últimos beneficios. Luzzato, 1950: 79-110; Triantaphyllopoulos, 1963 , 109ss; Sherwin-White, 1973; Luzzato, 1974, 9-64; Bernhardt 1982, 343-352.

${ }^{28}$ La Colonia lulia llici Augusta, por lo que se desprende de lo anotado en las fuentes literarias y jurídicas, tendría con anterioridad al 77 d.C. la immunitas, alcanzando posiblemente a comienzos del siglo III d.C. -o un tiempo antes- el ius Italicum. González Román, 1994, 144. 
La opinión más general de la investigación se decanta por pensar que las tierras representadas en la placa catastral pertenecerian a una prefectura ${ }^{29}$ de Ucubi (Espejo, Córdoba) ${ }^{30}$. Sobre esta ciudad, Plinio (nat. 3 , 3,12 ) apunta que junto con otras de la Bética recibió el privilegio de la immunitas. Al contar con la immunitas - pero no con el ius Italicumlos individuos asentados no tendrían que pagar tributo por la tierra. Por ello también, aunque la tierra estuviese en manos de ciudadanos romanos o de peregrinos, sus ocupantes no podrían reivindicar la usucapio para acabar detentando, con el paso del tiempo, la propiedad de la misma (Daza y Ennes, 1993, 204).

Podríamos estar ante la centuriación de tierras pertenecientes a Ucubi destinadas a trabajos agropecuarios (Caballos Rufino, 1978, 289; Stylow, 1986, 311; Sáez, 1994, 107).

De todas formas, los posesores de una parcela en dicha prefectura de Ucubi, contarian con protección jurídica para evitar cualquier abuso o injusticia que no les permitiese actuar como verdaderos propietarios del suelo. El pretor peregrino, el pretor urbano y los magistrados en las provincias tutelarian sus derechos y sus bienes. Si bien esto es cierto, no hemos de olvidar que las acciones favorables de pretores y magistrados protegiendo las posesiones en las provincias resultaría más efectiva cuando se daba en el poseedor alguno de los requisitos necesarios para alcanzar la propiedad ex iure Quiritium: ciudadanía romana, peregrino o latino con ius commercii y/o ius Italicum del suelo (Volterra, 1986, 314).

\section{LA PROPIEDAD DE LOS FUNDOS PRO- VINCIALES}

Jurídicamente, la disponibilidad de la tierra por parte de los particulares provinciales se consideraba en primera y última instancia dependiente de una concesión de la autoridad $y$, por otra parte, se daba la imposibilidad de llegar a alcanzar el dominium ex iure Quiritium de sus terrenos ${ }^{31}$, dado que tal dominium era un ius propium civium Romanorum ${ }^{32}$, de ahí que Gayo (Gayo, 2, 7) haga la distinción entre los fundos itálicos o que gozaban del ius Italicum y los restantes en las provincias.

Durante el principado, todo aquello que era propiedad del Estado romano estaba protegido por medios especiales, encontrándonos, a su vez, una distinción en cuanto a su adscripción: podían ser del aerarium populi Romani (erario del pueblo romano) o del fiscus, integrando este último todo el patrimonio del principe, no siendo éste propietario del mismo, sino que como institución, el patrimonio sería hererado por el sucesor del princeps. Si bien es cierto ésto, también lo es el hecho de que a partir del emperador Claudio, el fiscus se identificaría con el aerarium (Ortega, 1991, 50).

En cuanto a las formas de propiedad/posesión por las que se regía el suelo en las provincias contamos con varias posibilidades. Esta tierra podía ser objeto de dominium o de in bonis esse $^{33}$ si había recibido el ius italicum. De lo contrario, sería, como hemos comentado, del Aerarium populi Romani, del fiscus o de un municipio. Por otro lado, la tierra de una ciudad federada pertenecía a los particulares -independientemente de que fuesen ciudadanos romanos o peregrinos- o a la propia ciudad. Finalmente, el resto del territorio provincial era de las comunidades o de los ciudadanos en un régimen también distinto del dominium y de la propiedad pretoria, permitiendo al titular su uso y su tenencia (Ortega, 1991, 51; Rascón, 2000, 190).

El tributo al que estaban sometidos los fundos provinciales (stipendium para las provincias senatoriales y tributum para las imperiales) era considerado por la jurisprudencia imperial como el reconocimiento del dominio que ejercía el populus Romanus en la disponibilidad del particular sobre el fundo provincial. Por tanto, se trataba de una

29 Las praefecturae aparecen definidas por los gromáticos como tierras que una colonia tenía en una ciudad vecina (Front. De Lim. 26, 6-10 y fig. 25 La, y, Front. De Cond. Agr. 49, 7-9 La). La razón de este tipo de tierras deberíamos buscarla en la falta de terreno en el momento en que se repartiría el ager disponible en una colonia, por lo que no habría más remedio que recurrir al existente en comunidades vecinas (Sic. Flac. De Cond. Agr. 159, 26-29; 160, 7-14 La). ${ }^{30}$ La colonia Claritas Iulia Ucubi (Espejo, Córdoba) es para algunos autores una fundación cesariana (Wiegels, 1978, 60 ) y para otros octaviana (Galsterer-Kröll, 1975, 127). En cualquier caso, lo que no tenemos precisado por las fuentes es si se trató de una colonia romana con pobladores que gozaban de los privilegios propios del derecho romano, o, más bien, se trató de una colonia de derecho latino. En Hispania no eran frecuentes las colonias de ciudadanos romanos, siendo la mayoría de derecho latino.

31 Sobre la possessio del ager publicus desde el punto de vista jurídico y de las fuentes literarias, Albanese, 1985, 7382; Ortega, 1991, 50.

32 Es decir, se trataba de una res propiedad del populus Romanus o del emperador.

${ }^{33}$ La forma de propiedad que se instaturaba cuando faltaba alguno de los requisitos para adquirir el dominium, o cuando se adquiriria la propiedad por medio de usucapio. 
possessio o de un usufructo, siendo a veces considerado, como hemos visto anteriormente, como una locatio de ager publicus, o incluso como enajenación. Los particulares en las provincias no podían ser propietarios de estos fundos, pero los usaban y disfrutaban como si lo fuesen (Gayo 2,$7 ; 2,21 ; 27 ; 31 ; 46$ ).

En consecuencia, a estos fundos no podrían aplicarse los modos de adquisición de la propiedad sobre las res mancipi (mancipatio, in iure cessio, usucapio), pudiéndose concebir, sin embargo, la transferencia de un particular a otro del derecho de disponer de ellos con la obligación de que el adquiriente continuase pagando el stipendium o el tributum. Como venimos viendo, funcionarian al margen de la tónica general provincial como si se tratase de un fundo privado aquellos que gozasen del ius italicum, siendo para estos posible la transmisión y adquisición por las vías formales antes comentadas (Gayo, 1, 120 y 2,14).

Evidentemente, esta situación perduraría durante la época que denominamos clásica para el derecho romano (Rizzi, 1936, 779-795; Dulckeit, Schwarz y Waldstein, 1989, 234-264; Grelle, 1991, 249-265; Ortega, 1991, 51). Más tarde, a finales del siglo III d.C., cuando se suprimiese la distinción entre fundos itálicos y fundos provinciales, sobre todo en las provincias, se produciría una verdadera accesión a la propiedad privada de la tierra.

Durante tiempo se dio esta situación. Tras la promulgación de sucesivas leyes agrarias, y como consecuencia de la multiplicación de las asignaciones en determinados territorios incluso en las provincias-, se irían formando grandes posesiones de tierra, con lo que la primitiva possessio, en muchos casos, se transformaría en propiedad de pleno derecho ${ }^{34}$.

Además, a lo largo del siglo III d.C. sobre todo a partir de la Constitución de Caracalla de 212 d.C.- comienzan a unificarse los diferentes tipos de propiedad en uno solo (dominium o propietas), evolucionando este proceso durante los siglos IV y $\vee$ d.C.

Será Justiniano en una de sus constituciones el que, en el año 530 , afirmase que el propietario era el legítimo dueño de aquellos bienes que siempre le habían pertenecido (C. $7,23,1)$. Contemplaba, por tanto, un único tipo de propiedad como un derecho exclusivo del dueño sobre la cosa, evidentemente, limitado por los derechos y los intereses de los otros integrantes de la colectividad social (Ortega, 1991, 52).

\author{
$\mathrm{M}^{\mathrm{a}}$ Carmen Santapau Pastor \\ Area de Historia Antigua \\ Dpto. de Prehistoria, Arqueologia, $\mathrm{H}^{\mathrm{a}}$ Antigua, \\ Filología Griega y Filologia Latina \\ Facultad de Filosofía y Letras \\ Universidad de Alicante \\ Apdo. 99 \\ 03080 Alicante \\ MCarmen.Santapau@ua.es
}

\section{BIBLIOGRAFÍA}

ABASCAL, J. M., y ESPINOSA, U., 1989: La ciudad hispanoromana. Privilegio y poder, Logroño.

ABASCAL, J. M., 1996: "Derecho latino y municipalización en Levante y Cataluña", Teoría y práctica del ordenamiento municipal en Hispania, 255-283, Vitoria.

ALBANESE, B., 1985: Le situazioni possessorie nel Diritto Privato romano, Palermo.

ALFÖLDY, G., 1987: Römisches Städtewesen auf der neukastilischen Hochebene, Heidelberg.

ALFÖLDY, G., 1998: "Hispania bajo los flavios y los Antoninos: consideraciones históricas sobre una época", De les estructures indigenes a l'organització provincial romana de la Hispània Citerior, itaca, Annexos, 1, 11-32, Barcelona.

ALONSO, A., CERRILLO, E., 1987: "Complejidad social y conquista romana", Jornades internacionals d'arqueologia romana. De les estructures indigenes a l'organització provincial romana de la Hispania Citerior, 463-470, Granollers.

ARIÑO, E., GURT, J. M. y MARTIN BUENO, M. A., 1994: "Les cadastres romains d'Hispanie: état actuel de la recherche", Structures rurales et sociétés antiques. Actes du Colloque de Corfou (14-16, mai 1992), 309-328, París.

ARIÑO, E. y DÍAZ, P., 1999: "La economia agraria de la Hispania romana. Colonización y territorio", SHHA, 17,153-192.

BLȦZQUEZ, J. Ma . y ALVAR, J., (eds) 1996: La romanización en Occidente, Madrid.

BERNHARDT, R., 1982: "Immunität und Abgabenpflichtigkeit bei römischen kolonien und munipien in den Provinzen", Historia, 31, 343-352.

BLEICKEN, J., 1974: "In provinciali solo dominium est vel Caesaris. Zur Kolonisationspolitik der ausgehenden Republik und frühen Kaiserzeit", Chiron, IV, 359-414.

BOZZA, F. 1942: "Gaio II, 7 e la proprietà provinciale", Athenaeum, XX, 66-85.

\footnotetext{
34 No podemos perder de vista que en ocasiones Roma dejaba intacto el sistema que se encontraba en funcionamiento dependiendo de los territorios que se anexionasen y no cambiaba siempre la condición jurídica del particular respecto a los fundos. Evidentemente, la excepción a esta consideración la encontrariamos en aquellos establecimientos coloniales donde se asignaban parcelas a ciudadanos romanos o latinos y que pasaban a organizarse con una estructura político-administrativa típicamente romana. En otros casos, los romanos, aun cuando reafirmaban que el dominio de las tierras correspondía al populus Romanus, dejaban en manos de las comunidades la organización y distribución de las tierras entre los particulares e incluso la periodización del cobro de los cánones y de los impuestos periodicos.
} 
BOZZA, F., 1943: "Gaio II, 7 e la proprietà provinciale", Athenaeum, $X X \mid, 13-20$.

BRADFORD, J., 1957: Ancient Landscapes, Londres.

BRAVO, G., 2001: Hispania y el Imperio, Madrid.

BRUNT, P. A., 1962: "The Army and the Land in the Roman Revolution", J.R.S, 52, 69-86.

CABALLOS, A., 1978: "Colonia Claritas lulia Ucubi", Habis 9, 273-291.

CAPOGROSSI, L., 1981: La terra in Roma antica. Forme di proprietà e rapporti produttivi. I (età arcaica). Roma.

CAPOGROSSI, L., 1982: Lagricoltura romana. Guida storica e critica, Roma-Bari.

CAPOGROSSI, L., 1984: La struttura della propietà e la formazione dei iura praediorum nell'età reppubblicana, Roma.

CAPOGROSSI, L., 1988: "Dominium e possessio nell'Italia romana", La proprietà e le proprietà, 141-182, Milán.

CARANDINI, A., 1989: "La villa romana e la piantagione schiavistica", Storia de Roma, IV, 101-200, Turín.

CARANDINI, A., 1995: "Il latifondo in epoca romana, fra Italia e province", AAVV., 1995: Du latifundium au latifondo. Un héritage de Rome, une création médiévale ou moderne?. Actes de la Table ronde internationales du CNRS organisée à L'Université de Montaigne-Bordeaux III (1719 décembre, 1992), 31-36, Paris.

CARCATERRA, A., 1967: Possessio. Ricerche di Storia e di Dommatica, Roma

CARRELLI, E., 1935: "Possessio vel usufructus in Gai II, 7", S.H.D.I., 379-391

CASTILLO, Ma . J., 1996: Espacio en orden. El modelo gromático-romano de ordenación del territorio, Logroño.

CAVALIERI, G., OLESTI, O. y MAYER, M., 2002: "L'apport des documents épigraphiques à l'étude des cadastres romains", Atlas historique des cadastres d'Europe II, Dossier 1TAÉpigraphie, Bruselas-Luxemburgo.

CHAO, J., MESA, J. F. y SERRANO, M., 1999: «Un nuevo bronce hallado en La Alcudia», Ciudades privilegiadas en el Occidente romano, 417-424, Sevilla.

CHOUQUER, G. y FAVORY, F., 1992: Les arpenteurs romains. Théorie et practique, París.

CURCHIN, L. A., 1994: "Juridical epigraphy and provincial administration", Roma y las provincias. Realidad administrativa e ideología imperial, 87-102, Madrid.

DAZA, J., 1990: Iniciación Histórica al Derecho Romano, Alicante.

DAZA, J. y ENNES, L., 1993: Instituciones de derecho privado romano, Alicante.

DECLAREUIL, J., 1958: Roma y la organización del derecho, México.

DE CHURRUCA, J., 1994: Introducción histórica al Derecho Romano, Bilbao.

DE MARTINO, F., 1985: Historia económica de la Roma antigua. Voll y II, Madrid.

DE MARTINO, F., 1989), "Latifondio ed agricoltura a schiavi", Parola del Passato, 44, 217-239.

DE MARTINO, F., 1993), "Le forme del lavoro nell'economia agraria romana", Parola del Passato, 48, 5-25.

DEL GIUDICE, F. y BELTRANI, S., 1995: Nuovo dizionario giuridico romano, Nápoles.

DILKE, O. A. W., 1971: The Roman Land Surveyors, Londres.

DILKE, O. A. W., 1979: Gli agrimensori di Roma antica, Bolonia.

DOPICO, Mª. D. y PEREIRA, G., 1993: "La gran inscripción de Remeseiros (CIL II; 2476). Sobre la forma jurídica de tenencia de la tierra entre los indígenas bajo dominio romano, // Congreso Peninsular de Historia Antigua, 633642, Coimbra.
DULCKEIT, G., SCHWARZ, F. y WALDSTEIN, W., 1989: Römische Retsgeschichte, Munich.

FAVORY, F., 1983: "Propositions pour une modélisation des cadastres ruraux antiques", Cadastres et espace rural. Approches et reàlités antiques. Table ronde de Besançon, 51-135, Paris.

FERNÁNDEZ NIETO, F. J., 1982: «El derecho en la Hispania romana», en Historia de España (dirigida por R. Menéndez Pidal), vol. II, 2, 159-213, Madrid.

FINLEY, M. I., 1977: L'economia degli antichi e dei moderni, Roma-Bari.

GABBA, E., 1985: "Per una interpretazione storica della centuriazione romana", Athenaeum, 73, 265-284.

GALSTERER, H., 1996: "Diritto latino e municipalizzazione nella Betica", en Teoria y práctica del ordenamiento municipal en Hispania. Revisiones de Historia Antigua II, 211-221, Vitoria.

GALSTERER-KRÖLL, B., 1975: "Zu den Spanischen städtelisten des Plinius", AEA, 48, 120-128.

GARCÍA FERNÁNDEZ, E., 2001: El municipio latino. Origen y desarrollo constitucional, Gerión, Anejos V, Madrid.

GARCIAA GARRIDO, M. J., 1993: Diccionario de jurisprudencia romana, Madrid.

GASCOU, J, 1979: "L'emploi du terme respublica dans l'épigraphie latine d'Afrique", MEFRA, 91, 383-398.

GÓMEZ ROYO, E., 1997: El régimen de las aguas en las relaciones de vecindad en Roma, Valencia

GONZÁLEZ ROMÁN, C., 1994: "Ius Italicum e Immunitas en las colonias romanas de Hispania", en Roma y las provincias. Realidad adminsitrativa e ideología imperial, 131-145, Madrid.

GONZÁLEZ ROMÁN, C., 1997: Roma y la urbanización de Occidente, Madrid.

GONZÁLEZ ROMÁN, C., 1999: "El trabajo en la agricultura de la Hispania romana", El trabajo en la Hispania romana, 119-206, Madrid.

GORGES, J. G., 1979: Les Villes hispano-romaines. Inventaires et problématique archéologiques, Paris.

GORGES, J. G. y NOGALES, T., (coords) 2000). Sociedad y cultura en la Lusitania romana, IV Mesa Redonda Internacional, Mérida.

GRELLE, F., 1990: "L'appartenenza del suolo provinciale nell'analisi di Gaio", Index, 18, 167-183.

GRELLE, F., 1991: "I poteri publici e la giuresprudenza fra Augusto e gli Antonini", Pani, M. (a cura di): Continuità e trasformazioni fra Reppublica e principato. Istituzioni, política, società, 248-265, Bari

GREENE, K., 1990: The Archaeology of the Roman Economy, Berkeley-Los Angeles.

HALEY, E. W., 1986: Foreigners in Roman Imperial Spain: Investigations of Geografical Mobility in the Spanish Provinces of the Roman Empire 30 B.C. -A.D. 284, Columbia.

HALEY, E.W., 1991: Migration and economy in Roman imperial Spain, Barcelona.

HINRICHS, F. T., 1974: Die Geschichte der gromatischen Institutionen. Untersuchungen zu Landverteilung, Landvermessung, Bodenverwaltung und Bodenrecht im römischen Reich, Wiesbaden

JIMÉNEZ SALCEDO, M. C., 1999: El régimen jurídico de las relaciones de vecindad en derecho romano, Córdoba.

KEAY, S. J., 1996: "La romanización en el sur y el levante de España hasta época de Augusto", en La romanización en Occidente, 147-177, Madrid

KEPPIE, .L, 1983: Colonisation and Veteran Settlement in Italy 47-14 B.C., Londres.

KEPPIE, L., 1984: The making of the Roman Army, New Jersey. 
LE ROUX, P., 1988: "Les villes de statut municipal en Lusitanie romaine", Les villes de Lusitanie romaine: hiérarchies et territoire, Paris, 1990, 35-49.

LE ROUX, P., 1995: Romains d'Espagne. Cités e politique dans les provinces. $/^{\circ}$ siècle av. J.-C.-l/1" siècle ap. J.C., Paris.

LÓPEZ PAZ, P., 1994: La ciudad romana ideal, 1. El territorio, Santiago de Compostela.

LUZZATO, G. I., 1950: "Apunti sul ius Italicum", R.I.D.A., 5, 79-110.

LUZZATO, G. I., 1974: "Sul regime del suolo nelle province romane. Spunti critici e problemática", Atti del Convegno Internazionale I diritti locali nelle province romane con particolare riguardo alle condizione giuridiche del suolo, 9-64, Roma.

MACMULLEN, R., 1963: Soldier and civilian in the later Roman Empire, Cambridge.

MANGAS, J., 1996: "Derecho latino y municipalización en la Meseta Superior", Teoria y práctica del ordenamiento municipal en Hispania. Revisiones de Historia Antigua II, 223-238, Vitoria.

MANGAS, J., 2001: Leyes coloniales y municipales de la Hispania romana, Madrid

MANN, J. C., 1983: Legionary recruitment and veteran settlement during the Principate, Londres.

MARIN, Ma A., Emigración colonización y municipalización en la Hispania republicana, Granada.

MATEO, A., 2001: Observaciones sobre el régimen juridico de la mineria en tierras públicas en época romana, Cuadernos Compostelanos de Derecho Romano, Santiago de Compostela.

MAYER, M. y OLESTI, O., 2001: "La sortitio de llici. Del documento epigráfico al paisaje histórico", Dialogues d'Histoire Ancienne, 27/1, 109-130.

MAYER, M. y OLESTI, O., 2002: "Le tirage au sort des lots coloniaux: la sortitio d'llici", Atlas historique des cadastres d'Europe I/, Bruselas-Luxemburgo.

MAZZARINO, S., 1974: "Ius Italicum e storiografia moderna", Atti del Convegno Internazionale sul tema: I diritti locali nelle province romane con particolare riguardo alle condizioni giuridiche del suolo, 357-372, Roma

MENTXACA, R., 1993: El senado municipal en la Bética hispana a la luz de la lex Irnitana, Vitoria.

MOATTI, C., 1993: Archives et partage de la terre dans le monde Romain ( $/ /^{e}$ siècle avant - ${ }^{e r}$ siècle après J.-C.). Collection de l'École Française de Rome, 173, RomaParis.

MORALES, J., 1995: Ley, jurisprudencia y derecho en Hispania romana y visigoda, Zaragoza.

NICOLET, C., 1982: II mestiere di cittadino nell'antica Roma, Roma.

OREJAS, A., y SASTRE, 1., 1999, "Fiscalité et organisation du territoire dans le Nord-Ouest de la Péninsule lbérique: civitates, tribut et ager mensura comprehensus", DHA, 25/1, 159-188.

ORTEGA, A., 1991: La propiedad y los modos de adquirirla en derecho romano y en el código civil,

ORTIZ DE URBINA, E. y SANTOS, J. (eds), 1996: Teoria y práctica del ordenamiento municipal en Hispania, Revisiones de Historia Antigua II, Vitoria.

ORTIZ DE URBINA, E., 1996: "Derecho latino y municipalización virtual en Hispania, Africa y Gallia", Teoria y práctica del ordenamiento municipal en Hispania. Revisiones de Historia Antigua II, 137-153, Vitoria.

ORTIZ DE URBINA, E., 2000: Las comunidades hispanas y el derecho latino, Vitoria.

PENA, M. J., 1994: "Importance et rôle de la terre dans la première période de la presence romaine dans la Péninsule lbérique", Structures rurales el sociétés antiques, Actes du Colloque de Corfu (14-16 mai 1992),329-337.

PÉREZ CENTENO, M. R., 1999: Ciudad y territorio en la Hispania del siglo III d.C., Valladolid.

PONSICH, M., 1974: Implantation rurale surle Bas Guadalquivir, l, Madrid.

PONSICH, M., 1979: Implantation rurale surle Bas Guadalquivir, II, Madrid.

PREMERSTEIN, A. R. V., 1918: "/us Italicum", RE, X col. 1238-1253, Stuttgart.

RAMOS, R., 1974: De Heliké a llici, Alicante.

RAMOS, R., 1975: La ciudad romana de llici, Alicante.

RAMOS, R y UROZ SÁEZ, J., 1992: "llici", La conquista romana y modos de intervención en la organización urbana y territorial, DdA, 1-2, 95-104.

RASCÓN, C., 2000: Manual de Derecho Romano, Madrid.

RIZZI, M. A., 1936: Tratado de derecho privado romano, Buenos Aires.

RODDAZ, J. M., 1996: "Pouvoir et provinces: remarques sur la politique de colonisation et de municipalisation de Rome dans la Peninsule Iberique entre Cesar et Auguste", en Teoria y práctica del ordenamiento municipal en Hispania. Revisiones de Historia Antigua II, 13-15, Vitoria.

RODRIGUEZ NEILA, J. F., GONZÁLEZ ROMÁN, C., MANGAS, J. y OREJAS, A., 1999: El trabajo en la Hispania romana, Madrid.

RODRIGUEZ NEILA, J. F. y NAVARRO, F. J. (eds), 1999: Élites y promoción social en la Hispania romana, Pamplona.

ROLDÁN, J. M., 1974: Hispania y el ejército romano. Contribución a la historia social de la España antigua, Salamanca.

ROLDÁN, J.M., 1976: “El ejército romano y la romanización de la península lbérica”, $H A, \mathrm{VI}, 125-145$.

ROLDÁN, J. M., 1989: "Colonización y municipalización durante la República (de la II Guerra Púnica hasta César), Aspectos de la colonización y municipalización de Hispania, 13-31, Mérida.

ROLDÁN, J. M., 1996: "Un factor de romanización de la España romana imperial: el ejército hispánico", La romanización en Occidente, 101-123, Madrid.

ROLDÁN, J. M., 1998: "El papel social del ejército republicano romano en Hispania", Italia e Hispania en la crisis de la República romana, Actas del III Congreso HispanoItaliano (Toledo, 20-24 septiembre 1993), 233-242, Madrid.

SÁEZ FERNÁNDEZ, P., 1990: "Estudio sobre una inscripción catastral lindantes con Lacimurga", Habis 21, 205-227.

SÁEZ FERNÁNDEZ, P., 1994: "Nuevas perspectivas en relación a la ordenación territorial del sur de la Lusitania española", en Les campagnes de Lusitanie romaine. Occupation de sol et habitats, 99-108, Madrid-Salamanca.

SALMON, E. T., 1969: Roman colonization under the Republic, Londres.

SANTOS, J., 1998: "Comunidades indigenas y centros urbanos en Hispania en el proceso de conquista y organización de los territoros conquistados", El proceso de municipalización en la Hispania Romana, 11-38, Valladolid.

SAQUETE, J. C., 2000: Privilegio y sociedad en Augusta Emerita: la cuestión del lus Italicum y la Immunitas", Sociedad y cultura en la Lusitania romana, IV Mesa Redonda Internacional, 379-389, Mérida.

SAVIGNY, F. C., 1850: “Über das lus Italicum”, Vermischte Schriften I, 320-352.

SCHMIDLIN, B. y CANNATA, C. A., 1984: Droit Privé Ro- 
main. I. Sources, Famille, Biens, Genève.

SIMMEL, G., 1983: "Soziologie des Raumes", en Schriften zur Soziologie. Eine Auswahl, 221-242, Frankfurt.

STYLOW, A. U., 1986: "Apuntes sobre epigrafía de época flavia en Hispania", Gerion, 4, 285-311.

TRIANTAPHYLLOPOULOS, J., 1963: "Ius Italicum personnel", Iura, 14, 109ss.
VILLERS, R., 1977: Rome et le droit privé, París.

VOLTERRA, E., 1986: Instituciones de derecho privado romano, Madrid.

WIEGELS, R., 1985: Die Tribunsinschriften des Römischen Hispanien, Berlín.

ZACCARIA, A., 1995: Spazio privato e spazio publico nella cittá romana, Roma. 